\title{
Democratização do ingresso na educação superior: liames com a teoria marxista
}

\author{
Maria das Graças Martins da Silva \\ Tereza Christina Mertens Aguiar Veloso \\ Universidade Federal do Mato Grosso
}

\section{Resumo}

Este texto discute a democratização nas políticas de ingresso na educação superior, segundo a mediação teórica de Marx, Lukács e Wood. São utilizadas fontes documentais e bibliográficas, destacando os formatos seletivos de ingresso. Do estudo extrai-se a complexidade do sentido de democracia, um conceito implicado nas contradições sociais, na transformação da sociedade e na compreensão de ser humano. Igualmente, é possível apreender um discurso de infalibilidade e redenção sobre o ingresso na educação superior, cuja realidade, no entanto, ocorre de forma limitada e contraditória.

Palavras-chave: Educação superior. Políticas de ingresso. Democratização. 


\section{Democratization of admission into higher education: bonds with marxist theory}

This text discusses the democratization on admission policies in higher education, according to Marx, Lukács and Wood's theoretical mediation. It is based on documentary and bibliographic sources, highlighting the selective modes of entry. The study brings to light the complexity of the meaning of democracy, a concept involved in the social contradictions, in the transformation of society and in the understanding of being human. It is also possible to apprehend a discourse of infallibility and redemption regarding admission into higher education, while in reality, it occurs in a limited and contradictory fashion.

Keywords: Higher education. Admission policies. Democratization.

\section{Democratización del acceso a la educación superior: conexiones con la teoría marxista}

El texto analiza la democratización de las políticas de admisión en la educación superior, de acuerdo con la mediación teórica de Marx, Lukács y Wood. Se utilizan fuentes documentales y bibliográficas, destacando los formatos de entrada selectivos. A partir del estudio, se extrae la complejidad del significado de la democracia, un concepto implicado en las contradicciones sociales, en la transformación de la sociedad y en la comprensión del ser humano. Además, es posible aprender un discurso de la infalibilidad y de la redención acerca de la admisión en la enseñanza superior, cuya realidad, sin embargo, se produce así limitada y contradictoria.

Palabras-clave: Educación superior; Políticas de admisión; Democratización. 


\section{Introdução}

Nas políticas educacionais, sobretudo nas que se manifestam desde a década de 2000, a associação ao atributo "democrático" é recorrente, o que se observa nitidamente na abordagem da expansão e do acesso à educação superior. (Silva; Nogueira, 2001; Silva; Veloso, 2012)

A par disso, o texto que se apresenta tem por objetivo discutir a democratização nas políticas de ingresso na educação superior, o que se faz pela exposição dos formatos seletivos a esse nível de ensino, segundo a mediação teórica de Marx, Lukács e Wood, realçando as reflexões que se articulam ao debate proposto. Tratase de um estudo que, respeitando o limite de sua extensão, busca interpretar o ingresso na educação superior, recuperando eventos históricos acerca do tema e articulando-os ao que se mostra presentemente nas políticas de acesso à educação superior.

0 estudo mostra que, na história recente, a "democracia capitalista" tende a se abrigar na esfera política, numa pretensão de apartar-se da efetiva condição socioeconômica dos indivíduos reais. Nesse caso, por analogia, ingresso na educação superior pode ser traduzido como a capacidade ou mérito individual, princípio consagrado socialmente, quadro no qual se deixa de considerar certas condições postas na realidade, ligadas, por exemplo, à origem social e escolar do candidato ao ingresso ou, ainda, à restrita oferta geral de vagas ou do curso de opção. Na perspectiva marxista, contudo, o poder político não se isola da materialidade, do que se manifesta concretamente. Nesse sentido, o debate passa a articular-se à igualdade social e à universalidade, permitindo questionar o mito da "capacidade de cada um".

Isso considerado, para uma interpretação mais substancial e abrangente da realidade, entende-se que a teoria que reflete o concreto seja o ponto de partida necessário.

\section{A democratização sob a democracia marxista: marco teórico fundante}

0 materialismo dialético constitui a base filosófica marxista que almeja alcançar explicações coerentes e racionais para os fenômenos da natureza, da sociedade, do pensamento (Triviños, 1987). No plano epistemológico e no processo de descobertas, talvez se possa afirmar que a sua principal pretensão seja atingir a essência de um fenômeno. Por essência, entende-se a representação dos traços peculiares, dos aspectos principais, próprios e internos do que se estuda. Integrada à essência, convive uma representação aparente do real. A aparência pode revelar a essência como mostrá-la parcialmente ou deformá-la; contudo, ambas estão 
dialeticamente relacionadas e se influenciam (Kosik, 2002). No processo de produção do conhecimento, o objeto de estudo apresenta-se inicialmente pela sua manifestação externa (aparêncial e, evoluindo, compreende-se a sua essência. É preciso atentar, igualmente, que a essência e a aparência próprias de um fenômeno evidenciam-se na relação que constitui com outros fenômenos, ou seja, constitui-se "[...] do que é introduzido do exterior, do que é condicionado pela ação da realidade que rodeia o objeto, isto é, de outros objetos que the estão ligados." (Cheptulin, 2004, p. 278)

Na visão de Frigotto (1997), o materialismo dialético procura explicações coerentes e racionais para os fenômenos, com base em que a realidade representa uma totalidade e está em movimento histórico, imersa em relações sociais contraditórias. Para o autor, o método remete a questões múltiplas, entre as quais: como se produz concretamente determinado fenômeno social? Quais são as leis que impulsionam o seu desenvolvimento, a sua dinâmica, a transição de uma forma para outra? Que forças o constituem? Assim, trata-se de captar o objeto em movimento, identificando a sua trajetória e o que "está sendo", de forma datada e situada.

Parte-se, então, de que compreender uma realidade implica situar as perspectivas ontológico-filosófica e social-histórica, fios condutores gerais que possibilitam elaborações e explicitações específicas.

A perspectiva ontológico-filosófica marxiana evidencia conceitos que expressam a compreensão do ser humano, o ponto de partida decisivo. Marx (2005) concebe que o indivíduo é, imediatamente, um ser natural, munido de forças vivas e ativas que nele existem como possibilidades, como pulsões. A par disso, é também um ser dependente e limitado, porque os objetos de sua necessidade (alimento, reprodução, abrigo, sociabilidade) estão fora dele. E, se deles precisa vitalmente para a sua sobrevivência e afirmação, então, objetos e ser estão ligados, comprometidos de modo orgânico. Portanto, a busca por satisfazer a necessidade vital fora de si (na natureza) produz, além do ser natural, o ser social. Quer dizer, a sociedade (a sociabilidade) realiza a plena unidade do indivíduo com a natureza, com os semelhantes e consigo mesmo, desenvolvendo um processo de completude e de complementação, que o humaniza. Em outras palavras, o ser natural torna-se social-histórico na medida em que busca satisfazer suas necessidades vitais, mediando-as com a natureza; para tanto, precisa lançarse, disponibilizar, realizar, suprir, e, nesse processo complexo, desenvolve-se, cria-se, completa-se, humaniza-se e, ao mesmo tempo, humaniza o que o cerca. Finalmente, por consequência, há o reconhecimento do ser genérico, que decorre do compartilhamento com outros semelhantes, a sua espécie, o seu gênero, de modo que aquilo que o ser individual produz é para si e para o outro e viceversa. Concebe Marx (2005) que é na sociedade que se dá a unidade essencial dos indivíduos com a natureza, é onde acontece sua realização; ou seja, o florescimento pleno individual condiciona-se a sua realização no social. Não 
é, portanto, possível existir liberdade ou plenitude individual independente do coletivo. Heller (1970) completa pela afirmativa de que a autofruição apenas se converte em possibilidade social se for universal, se houver superação da alienação social; fora dessa condição, podem acontecer experiências pessoais, todavia, com dimensão representativa e excepcional.

Eagleton (1999, p. 35) considera que os escritos de Marx têm:

[...] o objetivo de identificar, e trabalhar no sentido de desmontar as principais contradições sociais que no presente nos impedem de viver o que veríamos como uma vida verdadeiramente humana, em toda a riqueza de nossos poderes corporais e espirituais.

Assim, para concretizar o ser natural, social, genérico, há de considerar as condições objetivas que determinam as relações sociais. No entanto, sem descuidar de que se trata de uma determinação complexa, visto que “[...] são os homens que, desenvolvendo suas relações materiais, transformam, com a realidade que thes é própria, seu pensamento e também os produtos do seu pensamento" (Marx, 2002, p. 19). Criando coisas e ideias, os seres evoluem, desenvolvem novas coisas, novas ideias, novos contextos e determinações. Assim, tem-se que os indivíduos, submetidos às condições objetivas, exercem influência sobre as mesmas, reforçando-as, alterando-as, superando-as.

0 debate do ser social interessa na medida em que a interpretação dos fenômenos materiais submete-se a tal fundamentação. Ou seja, por seus reflexos, os fundamentos ontológicos antecedem e percorrem o tratamento específico de quaisquer temáticas. Para o que se elege como estudo democratização e ingresso na educação superior - não poderia ser diferente.

Resta, ainda, explicitar a ideia geral de que a democracia se refere a um conceito com grau elevado de abstração, o qual pode "tornar-se" ação concreta pela democratização. Democratizar, então, pode vir a ser o acontecimento da democracia, seguindo avanços permanentes, infindáveis, que se constituem pela ação humana. Para Lefebvre (1979, p. 101), nesse sentido, no pensamento marxista, não existe uma "verdadeira democracia", posto que a mesma consiste, essencialmente, na "luta pela democracia", "jamais completamente vitoriosa, porque, em virtude de suas contradições, a democracia pode sempre avançar e regredir". Portanto, trata-se de uma construção dialética, pautada em momentos de afirmação, de negação e de superação de eventos ou ideias, permanentemente.

Com vista a aprofundar o que se anuncia, recorre-se a Lukács e Wood, autores que enfocam a democracia em parte da sua vasta obra. Neles, manifesta-se a referência ontológica marxiana, de modo a oferecer rica interpretação da temática que o presente texto privilegia. 


\section{Democracia e democratização em Lukács}

A reflexão que ora se faz tem base em "O Processo de Democratização", de György Lukács (2008)1. Na trilha de Marx, o autor parte de que a democracia precisa ser tratada de um ponto de vista histórico, como força política concreta e inserida numa formação econômica particular, terreno em que ela nasce, realiza-se, problematiza-se, refaz-se, transforma-se. Fora desse entendimento, afirma, criam-se fetiches, avaliações positivas ou negativas que não esclarecem; ao contrário, confundem a leitura dos processos sociais. E, porque é imperativo examinar a evolução histórica do real para bem conceituar o problema, o autor prefere usar o termo democratização, que pretende significar um processo, ao contrário do que é estático.

Lukács (2008) avalia que a democracia burguesa representa uma falsa alternativa diante da perspectiva de construção do socialismo, visto se basear no aparato jurídico ("cidadania") e em generalizações abstratas que não levam em conta a práxis humana. Para ele, a fim de tornar aceitável uma realidade deturpada, recorre-se a formas ideológicas caricaturais acerca da liberdade, propriedade, direitos, o que naturaliza a desumana a vida social sob o capitalismo. Lukács (2008, p. 100) reconhece as mudanças operadas na superestrutura política do sistema, contudo, reitera que a sua estrutura fundamental permanece intacta: “[...] o capitalismo atual constitui não a superação, mas o potenciamento, a difusão e o aprofundamento do caráter problemático que faz parte de sua própria natureza." Em tal contexto social, democratizar traduz-se pelo consumismo, convertendo toda a práxis humana no "fetiche da liberdade do comprar e vender." Contudo, mesmo reconhecendo a força da crítica, o filósofo entende que a recusa da democracia burguesa não se sustenta apenas em declarações dogmáticas em prol do socialismo; por isso, conclama a apreensão dos componentes históricosociais para buscar "uma correta formulação dos problemas da democratização hoje possível e necessária." (Lukács, 2008, p. 106)

Para Lukács (2008, p. 117), não se trata de simplesmente "ampliar a democracia", visto que representa subordinação ao sistema capitalista, ao contrário, trata-se de desenvolver outra abordagem de democracia, a que tenha por base material o "ser ontologicamente social que está sendo construído". Por isso, "a tarefa da democracia é penetrar realmente na inteira vida material de todos os homens, desde a cotidianidade até as questões decisivas da sociedade; é dar expressão à sua sociabilidade enquanto produto da atividade pessoal de todos os homens". Ao vincular a vida social ao cotidiano, Lukács (2008) ressalta as transformações qualitativas, aquelas que remetem à raiz do agir humano, consagrando hábitos, comportamentos, tradições - que tanto podem ser elementos

1. Trata-se de um ensaio escrito em 1968, aos 83 anos de vida de György Lukács. 0 texto compõe a obra "Socialismo e Democratização. Escritos políticos 1956-1971", que reúne um conjunto de publicações do filósofo húngaro. 
de profunda transformação social como nocivos, dependendo do que expressam.

Diante disso, apresenta-se o problema da transição de um modelo de organização social para outro. Lukács (2008, p. 125) argumenta que as decisões táticas (imediatas, emergenciais) "são momentos parciais do grande desenvolvimento histórico do gênero humano", isto é, são momentos que devem levar em conta e promover a sociabilidade universal. Isso significa não opor nem sobrepor questões pontuais às de longo alcance, e sim, articular o sentido de uma a outra, produzindo uma prática social em que ambas sejam consideradas em conexão. Assim, o autor estabelece um marco que contribui para situar o presente, sem declinar das aspirações que o transcendem.

Ainda se pode afirmar que, provavelmente, a contribuição central de Lukács no trato da democracia esteja na defesa intransigente do humanismo, daí seu rico feixe teórico com Marx. Ao se referir à "última e altamente evoluída forma de antihumanismo", desenvolvida pelo e no sistema capitalista, o autor a expressa como a "que considera a outra pessoa como limite, como mero objeto, como possível adversário ou inimigo da própria práxis de autorrealização" (Lukács, 2008, 192). Nada mais oportuno para se pensar sobre o acesso à educação superior, diante da pretensão, ou da ilusão, de qualificá-lo como democrático.

\section{Democracia e democratização em Wood}

No exame da democracia que Wood (2003) realiza, a história está no centro, o que significa situá-la diante do modo de produção social. Por desdobramento, para a autora, a questão fundamental está em identificar e reconhecer a coexistência da situação de classe com a "democracia formal", entendendo que ambas se revitalizam reciprocamente no tecido social. Argumenta ela que a conquista da democracia formal representou um avanço histórico, mas, sob a base capitalista, implicou o confinamento da esfera política à econômica, de maneira que esta passa a ter "regras próprias".

Wood (2003) pretende mostrar, essencialmente, que as relações capitalistas de propriedade consumaram a democracia sob a ideia de que o exercício político resume-se ao parlamento, ao voto, ao sistema de representação, o que repercute na construção de um indivíduo isolado, sem laços solidários e comunitários, com interesses concentrados nas dimensões de produção e de consumo. Ou seja, aniquila-se a ideia (e a sociabilidade) amparada em uma vida coletiva, igualitária, participativa em essência.

Do ponto de vista da democracia capitalista, explica a autora que o exercício da cidadania não é determinado pela posição socioeconômica, e sim pelo que se convencionou chamar de "exercício de direitos políticos". Assim, a "liberdade política" efetiva-se sem afetar ou alterar a desigualdade de classe, de modo 
a resguardar a contradição objetiva entre capital e trabalho e possibilitar a coexistência sem entraves entre "liberdade política" e relações de propriedade e poder desiguais. Nessa forma de se expressar a democracia, o poder popular é diluído, controlado, esvaziado, modelo que se consolidou e difundiu pela experiência norte-americana.

A república americana estabeleceu firmemente uma definição de democracia em que a transferência do poder para os "representantes do povo" constituiu não somente uma concessão necessária ao tamanho e à complexidade, mas a própria essência da democracia em si. Os americanos então, apesar de não terem inventado a representação, podem receber o crédito pelo estabelecimento de uma ideia constitutiva essencial da democracia moderna: a identificação desta com a alienação do poder. (Wood, 2003, p. 188)

A seu ver, a reformulação ${ }^{2}$ da ideia de democracia tende a associar-se à sátira, hipocrisia, jogos de interesses e duplicidades, provocando desprezo da política, no sentido de participação efetiva da população no funcionamento da sociedade.

Wood (2003) explica que, no liberalismo do século XIX, a classe dominante dividia-se entre a repugnância pela democracia e a sua inevitabilidade, dualidade que se tornava insustentável. Como "saída", a democracia foi redefinida, mantendo a submissão aos princípios do liberalismo nos seus traços fundantes (mercado, exploração do trabalho, propriedade, classes). Significava, pois, uma reconstrução ideológica, mediante uma assepsia do seu sentido transformador.

Seguindo a autora (2003), os efeitos da democracia sob o capitalismo produzem ambiguidades, uma delas relacionada à "transição suave da democracia capitalista para a socialista" ou à "realização das aspirações democráticas nos interstícios do capitalismo". Por isso:

É necessário, em primeiro lugar, não ter ilusões acerca do significado e dos efeitos da democracia no capitalismo. Isso representa não somente a compreensão dos limites da democracia capitalista [...], mas também, e ainda particularmente, a desvalorização da democracia [...]. (Wood, 2003, p. 233, grifos da autora)

A autora, assim, reforça os aspectos ideológicos envoltos na democracia, chamando atenção à possibilidade de se produzir "outra" realidade, a partir do que (e negando aquilo que) está posto objetivamente. Sob suas lentes, pode-se compreender a "educação superior democrática" como uma mitificação, ao se confrontar com a realidade.

A base teórica que se apresenta leva, ainda, ao entendimento de que a participação política refere-se a uma face da democracia, a qual,

2. Wood (2003, p. 174) estuda a redefinição da democracia capitalista a partir da comparação com a democracia antiga. "Somente no capitalismo se tornou possível deixar fundamentalmente intactas as relações de propriedade entre capital e trabalho enquanto se permitia a democratização dos direitos políticos e civis". 
verdadeiramente, dimensiona-se, define-se, explica-se pela condição efetiva do sujeito no contexto social. Ou seja, a democracia realmente se situa diante dos meios socialmente disponíveis para exercê-la.

\section{Para situar o ingresso na educação superior}

Com base no materialismo histórico dialético, a apreensão de um fenômeno se produz por meio do que se materializa na história e na realidade concreta. É o que se procura compor inicialmente mediante um breve inventário do ingresso na educação superior.

0 ensino superior no Brasil remonta ao período colonial ${ }^{3}$, pela oferta de cursos isolados, num tempo em que funcionava em colégios e seminários da ordem jesuíta (1572-1759). 0 ingresso, então, caracterizava-se pela ausência de barreiras classificatórias, visto que existiam vagas suficientes para atender ao restrito número de interessados.

A partir de 1808, o ensino superior foi se remodelando a fim de aproximarse das necessidades de reprodução da sociedade, que, gradativamente, tornavase mais complexa, passando a requerer profissionais liberais e ocupantes de cargos oficiais. Era imperioso, portanto, erguer certas dificuldades para propiciar a inclusão ao ensino superior, o que se expressou inicialmente pelos "exames preparatórios", prestados no estabelecimento de ensino procurado (Cunha, 2007). Em razão da pressão das elites pela participação na educação superior, seguiuse uma facilitação desses exames, o que permitiu que estudantes considerados despreparados frequentassem certos cursos.

Em 1890, a Reforma Benjamin Constant criou o "exame de madureza”, visando avaliar conteúdos dos concluintes do ensino secundário. Caso fossem aprovados, poderiam matricular-se em qualquer escola superior do país. Cunha (2007) destaca que a reforma significou a extensão do privilégio do ensino superior aos colégios organizados pelos governos estaduais, desde que adaptassem os currículos ao padrão nacional. Mas também significou a tentativa de frear a obtenção, de qualquer maneira, de um diploma superior, pressão que vinha das elites.

Já em 1911, a Reforma Rivadávia Côrrea fixou, pela primeira vez, diretrizes para o concurso de ingresso na educação superior, introduzindo o "exame de admissão" como forma de seleção.

Na sequência, em 1915, foi aprovada a Reforma Carlos Maximiliano (Decreto n. ${ }^{0}$ 11.530), que retirava dos diplomas do Colégio Pedro II e dos que the eram equiparados, o privilégio de garantir matrículas nas escolas superiores, bem como

3. Sobre o ensino superior na Colônia no Brasil, lembra Cunha (2007, p. 21) que o mesmo "[...] só pode ser entendido como atividade de um aparelho educacional posto a serviço da exploração da Colônia pela Metrópole”. Como exemplo, aponta que certos estudos, embora idênticos aos realizados em Portugal, necessitavam ter o reconhecimento desse país. 
definia os exames de admissão para a seleção dos candidatos ao ensino superior, passando a designá-los de "exames vestibulares". (Cunha, 2007)

Em 1925, a Reforma Rocha Vaz estabeleceu que cada faculdade fixasse o número de vagas oferecidas a cada ano. Assim, os estudantes aprovados seriam matriculados por ordem de classificação, até preenchidas todas as vagas. Os demais, para ingressar na educação superior, teriam que se submeter a uma nova classificação. A medida continha o fluxo de passagem para o ensino superior e diminuía o número de estudantes em certos cursos, remanejando-os para os menos procurados. Era, pois, a fase classificatória do ingresso.

Sinteticamente, esse movimento regulatório se caracterizou por tentativas de controle do ingresso no ensino superior, configurando embates que envolviam a pressão pela diplomação, a preservação de status mediante a participação limitada e a falta de respostas efetivas por parte do poder público.

0 Estatuto das Universidades Brasileiras (1931) foi representativo de um novo momento político e econômico no país, pautado no desenvolvimento industrial. Nesse sentido, evidenciava maior preocupação em organizar e controlar a educação superior, por exemplo, mediante critérios de autorização e reconhecimento de cursos - fator que repercutia na ampliação de vagas. Em relação ao ingresso na educação superior, o Estatuto manteve a admissão nos cursos pela aprovação nos exames vestibulares, que passam a se realizar pela natureza dos cursos almejados. (Souza, 2007)

No contexto do Estado Novo, a Reforma Gustavo Capanema, ou as Leis Orgânicas do Ensino (Decreto 4.244, de 09/04/1942), alterou a estrutura do ensino secundário para dois ciclos: o primeiro, com duração de quatro anos, e o segundo, composto por dois cursos paralelos, o clássico e o científico. Com a reforma, foram criados os exames de licença (exames de saída), aplicados aos estudantes que concluíssem o curso clássico ou o científico, dando o direito, se aprovados, a ingressar em qualquer curso do ensino superior. Contudo, esses exames foram extintos pelo Decreto 9.303, de 27/05/1946.

Mais adiante, nos anos 1960, a questão do ingresso na educação superior ganhou maior centralidade, na tentativa de responder a eventos sociais diversos e articulados: o crescente número de concluintes do ensino secundário, a restrição de vagas, os conglomerados urbanos e a economia carente de mão de obra especializada e diversificada. Nessa direção, a Lei de Diretrizes e Bases da Educação (LDB - Lei n. ${ }^{0} 4.024$, de 1961) eliminou o princípio da gratuidade do ensino oficial, abrindo possibilidade de que os ensinos médio e superior cobrassem anuidades. Ao mesmo tempo, previu a aplicação de mecanismos de concessão de bolsas e outras formas de cooperação ao ensino particular. A LDB, embora sem alterar o Estatuto das Universidades Brasileiras de 1931, facilitou o ingresso das camadas médias ao ensino superior, ao instituir “... a equivalência entre os diversos ramos dos cursos de Ensino Médio, possibilitando o ingresso na Educação Superior a todos os egressos de qualquer curso de Ensino Médio e 
trazendo tendências favoráveis ao sistema privado de ensino". (Souza, 2007, p. 83)

Até então, eram considerados aprovados todos os candidatos que atingissem a média mínima requisitada no exame. Dessa forma, foi surgindo um grande número de excedentes, candidatos aprovados com a nota mínima, mas que não ingressavam devido à falta de vagas. Criava-se, pois, uma situação insustentável para o Estado.

No desenlace da questão, é importante levar em conta as demandas do modelo desenvolvimentista, que necessitava de recursos humanos diplomados, gerando clamores por uma resolução rápida da questão do ingresso no ensino superior. ${ }^{4}$ Assim, no contexto do regime militar, a Lei ${ }^{0} 5.540$, de 1968, estabeleceu o vestibular classificatório e unificado por região e tipo de curso, configurando uma alternativa para tratar do problema dos excedentes. Em 1971, o Decreto 68.908, de 13/07/1971, consolidou a estratégia de controle do ingresso, definindo que seriam admitidos candidatos até o limite de vagas fixadas no edital, além de que o resultado nulo em qualquer prova os excluiria, sendo a classificação feita em ordem decrescente dos resultados. Em meio a essas regulações, crescia o ensino privado na forma de faculdades isoladas, aliviando, por essa via, a pressão provocada pela demanda. Vale destacar, conforme Borges e Carnielli (2005), que nas décadas de 1970 e 1980 normatizações foram estabelecidas (introdução da redação nas provas, vestibular por etapas, fixação de pesos diferentes por prova, provas de habilitação para certos cursos), parecendo corroborar com um quadro elitista, no qual restava aos segmentos populares opção pelo ensino particular, pela facilitação nos critérios de ingresso.

Vivia-se um momento de abordar o impasse do ingresso na educação superior. Reflexo disso foi o evento "Seminário sobre o Vestibular: dilemas do acesso ao Ensino Superior no Brasil", realizado em 1979, promovido pelo MEC e pelo Conselho de Reitores de Universidades Brasileiras. Bastante emblemático é o entendimento de democratização expresso por participantes, conforme a seguir descrito:

A verdadeira democratização do ensino superior não consiste em conduzir à universidade todos os jovens, indiferentemente de suas capacidades e aptidões, mas em fazer com que os que têm capacidade real e vocação para os altos estudos possam ir até o limite de suas potencialidades [...]. (Democratização..., 1979 apud Souza, 2007, p. 911

Coroando tal pensamento, identifica-se no documento do seminário um discurso muito atual, cuja sutileza mascara o contraditório que encerra: "A democracia não defende o nivelamento igualitário, mas a igualdade de oportunidades para a seleção dos melhores." (Souza, 2007, p. 91)

No que tange à legislação hoje vigente, a Constituição de 1988 faz menção (direta ou não) à questão do ingresso na educação superior em pelo menos três

4. Rossato (2005) mostra que, a partir da década de 1950, mundialmente, ocorrem mudanças no ensino superior que se relacionam a sua expansão, concorrendo para o ensino "de massas". Afirma que a elevação das taxas de escolarização situa-se no contexto econômico dos países e do conhecimento como fonte produtiva. 
dos seus artigos. 0 artigo 206 (IV) estabelece que o ensino seja ministrado com base no princípio da gratuidade do ensino público em estabelecimentos oficiais; 0 artigo 208 define que o dever do Estado com a educação será efetivado mediante a garantia de: "V- acesso aos níveis mais elevados do ensino, da pesquisa e da criação artística, segundo a capacidade de cada um; VI- oferta de ensino noturno regular, adequado às condições do educando"; o artigo 214 expressa que a lei estabelecerá o plano nacional de educação que conduza à universalização do atendimento escolar, entre outros aspectos.

Por sua vez, na Lei de Diretrizes e Bases da Educação (LDB - Lei n. ${ }^{9} 9.394$, de 1996), os artigos que se relacionam ao ingresso na educação superior podem ser assim resumidos: 0 artigo $2^{\circ}$ define que o ensino deve ser ministrado sob princípios, dos quais se destaca a igualdade de condições para o acesso e permanência na escola; artigo 44, que determina que a educação superior abranja os seguintes cursos e programas: "Il- de graduação, abertos a candidatos que tenham concluído o ensino médio ou equivalente e tenham sido classificados em processo seletivo"; artigo 49, que institui que "as instituições de educação superior aceitarão a transferência de alunos regulares, para cursos afins, na hipótese de existência de vagas, e mediante processo seletivo"; artigo 50, que prevê que "as instituições de educação superior, quando da ocorrência de vagas, abrirão matrícula nas disciplinas de seus cursos a alunos não regulares que demonstrem capacidade de cursá-las com proveito, mediante processo seletivo prévio"; artigo 51, expressa que: "As IES credenciadas como universidades, ao deliberar sobre critérios e normas de seleção e admissão de estudantes, levarão em conta os efeitos desses critérios sobre a orientação do ensino médio, articulando-se com os órgãos normativos dos sistemas de ensino."

A LDB, ao designar "processo seletivo" (artigo 44), consente inovações na forma de ingresso, o que foi regulamentado pelo Parecer CNE/CP 95, de 02/12/1998, que apresenta alternativas ao vestibular, entre as quais o Exame Nacional do Ensino Médio - Enem. A propósito, conforme Gomes e Lima (2010), a diversificação dos processos seletivos apoia-se no discurso de que o vestibular tradicional tinha por base um ensino livresco e memorístico e que era necessário produzir maior ligação entre as universidades e o ensino médio.

O Enem (criado pela Portaria MEC 438, de 28/05/1998) foi emblemático para balizar a mudança de orientação na forma de ingresso na educação superior e destaca-se pela crescente adesão das instituições de ensino. Inicialmente, sua função primordial era avaliar o desempenho do estudante ao fim da escolaridade básica, e, com isso, auxiliar na elaboração de políticas educacionais. As funções do exame foram sendo ampliadas, a exemplo de constituir-se em critério para certificação do ensino médio, financiamento do Fundo de Financiamento do Ensino Superior e concessão de bolsas de estudos em instituições de ensino privado.

A partir de 2009, uma novidade apresenta-se por meio do então denominado Novo Enem. A criação de uma nova forma de ingresso nas universidades 
federais consta no documento "Proposta à Associação Nacional dos Dirigentes das Instituições Federais de Ensino Superior" (2009). Sob o argumento de "democratização das oportunidades de concorrência às vagas federais de ensino superior", propõe-se um exame centralizado, que favoreceria os estudantes que não tivessem condições de se deslocar pelo país. O MEC reconhece a "necessidade, importância e legitimidade do vestibular" como "instrumento de estabelecimento de mérito" para o ingresso na educação superior; no entanto, considera que a descentralização dos processos seletivos "favorece candidatos com maior poder aquisitivo". Nesse sentido, a alternativa se apresenta pela unificação da seleção às vagas das Instituições Federais de Ensino Superior (IFES) por meio de uma prova única, sendo o Novo Enem anunciado, inclusive, como "instrumento de indução da reestruturação dos currículos do ensino médio".

A proposta é detalhada no "Termo de Referência. Novo Enem e Sistema de Seleção Unificada" (Brasil, 2009), que expõe sobre as possibilidades de utilização do modelo para ingresso na educação superior:

2. Essa utilização pode se dar de duas formas. A primeira, mediante simples informação, pelo Instituto Nacional de Estudos e Pesquisas Educacionais Anísio Teixeira - Inep, à IES, dos boletins de resultados dos candidatos que tiverem realizado o novo ENEM, adotado como prova de seleção com base em Edital próprio publicado pela IES, facultando-se sua utilização como fase única ou primeira fase do processo seletivo.

3. A segunda forma de utilização do novo ENEM consiste na adesão ao Sistema de Seleção Unificada, sistema informatizado do Ministério da Educação apto a processar o registro das vagas especificamente oferecidas pelas IES ("vagas ENEM"), em confronto com as listas ordenadas de candidatos, em ordem decrescente, por curso, segundo a pontuação no Exame. 0 pressuposto da adesão ao Sistema de Seleção Unificado é a utilização do novo ENEM como fase única, sem prejuízo de eventual realização de exame de aptidão para áreas específicas (desde que esse se dê em tempo compatível com o calendário da primeira e segunda chamadas do Sistema de Seleção Unificado). (Brasil, 2009)

Cabe destacar que o documento antes citado, “Proposta à Associação Nacional dos Dirigentes das Instituições Federais de Ensino Superior" (2009), defende que a centralidade do exame seletivo o tornaria "mais isonômico em relação ao mérito dos participantes." Emblematicamente, ao avaliar como baixa a taxa de mobilidade dos ingressantes nas unidades da Federação no Brasil (0,04\%), o documento a compara à registrada nos Estados Unidos, onde 19,2\% residem fora do estado de origem.

É ainda interessante atentar para os depoimentos dos Ministros da Educação, Fernando Haddad e Aloizio Mercadante, gestores sucessivos do referido modelo de ingresso, reproduzidos abaixo, respectivamente:

Estamos sintonizando o Brasil com os melhores sistemas universitários (chinês, 
americano, francês, alemão), que não têm esse expediente de cada instituição fazer o seu processo seletivo [...] Nós estamos reorganizando o ensino médio em bases racionais e lógicas. Haverá, portanto, um reforço da questão do mérito. $(0$ fim do vestibular..., 2012)

O Brasil precisa ter convicção de que nenhum país desenvolvido deixa de usar instrumento semelhante ao Enem. A China tem um exame que o aluno pode fazer uma única vez na vida. Alemanha, Itália, França e Grã-Bretanha têm prova uma vez por ano. 0 Enem é critério de meritocracia num Estado republicano, especialmente entre os mais pobres. (Mercadante quer dar bônus..., 2012)

Percebe-se o afã em alinhar o Brasil aos modelos de educação superior considerados bem sucedidos em países do chamado "bloco desenvolvido". Junto a isso, insiste-se no argumento do mérito.

Mas, afinal, qual é o mérito do mérito, senão o de classificar, selecionar? Em outras palavras, permitir que seja aceito socialmente o fato de que não há vagas para todos, apenas para os considerados melhores. Entretanto, apurar a inteligência ou o que se convencionou chamar de competência do candidato, convenientemente, faz esquecer que esses traços são condicionados pela trajetória não apenas escolar, mas de vida particular, social, cultural, e, inclusive, envolve o episódico, o imediato, o circunstancial (o "momento da prova"). Ao se desconsiderar esse universo complexo de condições, decreta-se uma sentença, na maioria das vezes, condenatória aos candidatos excluídos. Em nome do mérito, como fosse o fiel da balança, um ente neutro, isento, imaculado, à parte de condicionamentos.

A propósito, não se pode esquecer que a Constituição Federal, em seu artigo 208, respalda que o acesso se realize “segundo a capacidade de cada um”, legitimando, portanto, o sentido de atribuição individual do sucesso ou do fracasso na vida escolar, e, com isso, contribuindo para retirar ou minimizar a responsabilidade social implicada.

Pesquisas sobre ingresso na educação superior, seja com base no vestibular tradicional (Zago, 2006) ou em programas alternativos de ingresso, como a avaliação seriada (Borges; Carnielli, 2005), mostram que há forte relação entre seletividade escolar e seletividade social, ambas marcadas pela estratificação social. Igualmente, mostram que há hierarquia na escolha dos cursos, conforme os estratos sociais. Borges e Carnielle (2005) expressam: “Os candidatos não concorrem em situação de igualdade. Há uma disputa entre desiguais por causa da estratificação social".

Como parte do enfrentamento dessa questão, absorvendo uma demanda dos movimentos sociais, em 2010, aprovou-se o Estatuto da Igualdade Racial (Lei n. ${ }^{0}$ 12.288, de 20/07/2010), cuja norma é “destinada a garantir à população negra a efetivação da igualdade de oportunidades, a defesa dos direitos étnicos individuais, coletivos e difusos e o combate à discriminação e às demais formas 
de intolerância étnica" lartigo 10). No campo da educação, o artigo 15 prevê a adoção de programas de ação afirmativa. Aqui, portanto, apresenta-se uma demanda que o sistema integra, minimizando uma situação de vulnerabilidade ao seu próprio funcionamento, mas que significa a inclusão de parte significativa da população alijada por décadas de um bem social fundamental.

Nessa esteira, é aprovada a Lei n. ${ }^{0} 12.711$, de 29/08/2012, que dispõe sobre o ingresso nas universidades federais e nas instituições federais de ensino técnico de nível médio. 0 texto define que:

Art. $1^{\circ}$ As instituições federais de educação superior vinculadas ao Ministério da Educação reservarão, em cada concurso seletivo para ingresso nos cursos de graduação, por curso e turno, no mínimo 50\% (cinquenta por cento) de suas vagas para estudantes que tenham cursado integralmente o ensino médio em escolas públicas.

Parágrafo único. No preenchimento das vagas de que trata o caput deste artigo, 50\% (cinquenta por cento) deverão ser reservados aos estudantes oriundos de famílias com renda igual ou inferior a 1,5 salário-mínimo (um salário-mínimo e meio) per capita.

[...]

Art. $3^{\circ} \mathrm{Em}$ cada instituição federal de ensino superior, as vagas de que trata 0 art. $1^{0}$ desta Lei serão preenchidas, por curso e turno, por autodeclarados pretos, pardos e indígenas, em proporção no mínimo igual à de pretos, pardos e indígenas na população da unidade da Federação onde está instalada a instituição, segundo o último censo do Instituto Brasileiro de Geografia e Estatística (IBGE). (Brasil, 2012)

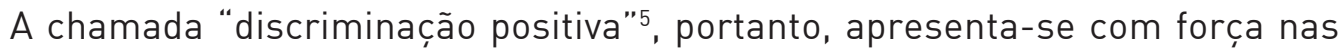
políticas da educação superior a partir da década de 2000. É possível afirmar que corresponde a medidas reparadoras, cujo valor está no reconhecimento e no trato de questões emergenciais e resultantes da extrema e histórica desigualdade social, encravadas na sociedade ao longo de muitas décadas e que exigem ação urgente.

Nessa linha, é expressiva a análise de Marx, em Crítica ao Programa de Gothab, de que a igualdade baseada na "unidade de medida comum", indistintamente, sem considerar as distinções de classe e outras lo que no texto original significavam as "diferenças físicas e intelectuais") contém uma "igualdade desigual". Referindose à aplicação da medida comum sobre o produto do trabalho e sua partilha, ele declara: "Esse direito é um direito desigual para um trabalho desigual [...]. Portanto, no seu conteúdo, é um direito baseado na desigualdade como todo direito." Como se nota, Marx sugere que, no âmbito de um sistema desigual, o combate à desigualdade precisa considerar certas desigualdades específicas.

5. Ações deliberadas que visam favorecer grupos em situação de desvantagem quanto ao acesso a bens públicos.

6. Obra escrita em 1875. Disponível em: <http://www.marxists.org>. Acesso em: 17 abr. 2007. 
Contudo, reconhecer a validade das ações afirmativas também é reconhecer o seu caráter transitório, emergencial, compensatório. Por isso, há de ter em vista o crescimento radical de vagas públicas, visando à universalidade do ingresso, o que tornaria possível decretar a inutilidade das ações afirmativas.

0 debate precisa considerar, ainda, que a taxa de escolaridade líquida da educação superior (jovens de 18 a 24 que frequentam esse nível de ensino), em 2009, era de 14,4\%. De igual forma, em 2011, de acordo com os dados do Censo da Educação Superior, grande parte da oferta de vagas estava no setor privado, que representava $88 \%$, enquanto no público era de $12 \%$ (Brasil, 2013). Tais números expressam a falta de vagas em geral, e, em específico, no setor público, o que contribui para agravar a situação dos discriminados socialmente.

Em síntese, como se registrou, ingressar na educação superior no Brasil traz na história a marca (às vezes velada) da restrição e do controle, o que se mantém vivo na atualidade, mesmo com facetas diversas. Viu-se, ainda, que a diversificação dos processos seletivos, a exemplo de cotas, avaliação seriada de histórico do ensino médio, testes de conhecimento, entrevistas, exame de currículo, exame unificado etc., preserva, em essência, as citadas características. É possível afirmar, portanto, que os formatos diversificados não têm alterado um quadro em que: al nas instituições públicas, via de regra, o ingresso segue competitivo e implica um ritual de passagem por cursos preparatórios, ainda que isso, em parte, possa ser atenuado pela introdução das ações afirmativas; b) nas instituições privadas, salvo raras exceções, segue a facilitação do ingresso, expressando o ensino como mercadoria rentável. Reiterando essa realidade, dados sobre a procura pelo nível superior, em 2011, informam que no setor público a concorrência era de 9,9 candidatos para cada vaga, enquanto no setor privado essa relação era de 1,2. (Brasil, 2013)

Parece possível afirmar que ao quadro regulatório e a certas políticas instituídas são atribuídos poderes resolutivos que se mostram irreais diante dos dados. Ao focar a educação superior, nesse sentido, difunde-se a ideia de que democratizá-la seja sinônimo de democracia plena, esquecendo-se de que a primeira transita nas veias do sistema que vige, ao passo que a segunda condiciona-se a sua superação.

Diante da realidade que se mostra, o discurso crítico exerce a função de apontar os avanços, sem deixar de evidenciar contradições e limites, em face do que se situa a análise de Lukács (2008, p. 25) de que as propostas pontuais, emergenciais (táticas) são como "momentos parciais do grande desenvolvimento histórico do gênero humano", isto é, são momentos que podem promover a "sociabilidade universal" - desde que não se cultive a ilusão de que resolvam 0 problema crucial da desigualdade.

\section{Apontamentos para uma síntese}


A ideia de democracia que norteia o texto refere-se ao usufruto coletivo dos bens produzidos socialmente. Assim sendo, “a plena realização da democracia implica a superação da ordem social capitalista", sistema em que se pode realizar apenas parcialmente (Coutinho, 2002, p. 17). Contudo, porque se vive concretamente sob as condições da sociedade capitalista, tem-se o desafio, no hoje, de perseguir a democracia em meio a contradições. Nesse sentido, democratização significa um processo de consubstanciação da democracia, uma junção de esforços para o seu alcance, avanços no interior da sociedade atual, aquilo que engendra mudanças na perspectiva da democracia efetiva.

A par desse entendimento, as possibilidades de democratização no estágio brasileiro capitalista de "neoliberalismo mundializado", acrescido por um histórico de acúmulo de desigualdades, pressupõe levar em consideração que o ingresso na educação superior tem se mantido elitista (corte de classe social e/ou de cor/raçal, o que significa, nesse momento, que certas políticas dão um passo para minorar desigualdades sociais crônicas. Entretanto, é preciso reconhecer seus limites, dada a incapacidade de abordar problemas em perspectiva estrutural e causal.

Nesse quadro, discutir a democratização nas políticas de ingresso na educação superior, tendo como inspiração as contribuições de Marx, Lukács e Wood, remete a algumas sínteses gerais, que se complementam e articulam: al o modelo de sociedade reflete-se no modelo de ingresso na educação superior, de modo que ambos, reciprocamente, se reforçam; b) a realização da democracia articula-se ao configurado no contexto social e às forças organizadas existentes; cl a ideia de democracia implica uma ideia inspiradora de realidade a ser construída, mediada pelas contradições e possibilidades em relação ao sistema social vigente; d) na construção de uma forma mais elevada de relacionamento humano, o conceito de democracia está enredado ao de igualdade social; el "alargar a democracia” é um imperativo do presente, ainda que não signifique, por si só, a superação dos problemas causais inerentes ao sistema de exploração; f) um projeto educacional democrático pauta-se na efetivação de condições objetivas que concretizem o ser social, de modo que ingressar na educação superior, democraticamente, atrela-se a esse projeto.

Dos autores estudados extrai-se como substância a complexidade na apreensão do sentido de democracia, posto ser um conceito implicado nas contradições sociais, na transformação da sociedade e na compreensão de ser humano. A chave, portanto, parece estar em acolher os estudos ontológicos e históricos para desvendar a democracia que se pauta num discurso de infalibilidade e redenção.

Como analisa Borges (2009): 
[...] o pleno acesso a melhores condições de vida implica, no limite, em igualdade material, o que está completamente fora das possibilidades do modo de produção capitalista, cuja base fundante está na exploração do trabalho, visando à acumulação. (Borges, 2009, p. 42)

Isso considerado, há entre a promessa e o usufruto universal dos bens coletivos um fosso; porém, não se trata de desprezar ou menosprezar medidas democratizantes, visto que, em condições determinadas, podem germinar processos sociais no sentido de transformações sociais.

Acolhendo o referencial indicado, conclui-se que "democratizar na direção da democracia" implica objetivamente expandir de forma radical a educação superior pública, de modo a possibilitar o ingresso universal e assegurar a formação qualificada, inspirando-se numa construção social igualitária. Isso reflete um projeto idealizado, que se constitui e se constrói a partir do que está posto na realidade atual, e, paradoxalmente, ao que se opõe a essa realidade.

\section{Referências}

BRASIL. Sinopse Estatística da Educação Superior 2011 - Graduação. Disponível em:<http://portal.inep.gov.br/superior-censosuperior-sinopse>. Acesso em: 30 jan. 2013.

. Lei 12.711, de 29 de agosto de 2012. Disponível em: <www. planalto.gov. br/CCIVIL_03/_Ato2011.../2012/Lei/L12711.htm>. Acesso em: 31 ago. 2012. . Proposta à Associação Nacional dos Dirigentes das Instituições Federais de Ensino Superior. Assessoria de Comunicação Social.Ministério da Educação. Disponível em: <http://portal.mec.gov.br/index.php?ltemid=310\&id=13318\&op tion=com_content\&view=article>. Acesso em: 17 mar. 2010.

BORGES, José Leopoldo das Graças Borges; CARNIELLI, Beatrice Laura Educação e estratificação social no acesso à universidade pública. Cadernos de Pesquisa, São Paulo, v. 35, n. 124, p. 113-139, jan./abr. 2005.

BORGES, Liliam Faria. 0 debate sobre a democracia na tradição histórica da social-democracia. In: ; MAZZUCO, Neiva Galina (Orgs.). Democracia e políticas sociais na América Latina. São Paulo: Xamã, 2009, p. 37-60.

CHEPTULIN, Alexandre. A dialética materialista. Categorias e leis da dialética. São Paulo: Alfa Ômega, 2004.

COUTINHO, Carlos Nelson. A democracia na batalha das ideias e nas lutas políticas do Brasil de hoje. In: Fávero, Osmar; SEMERARO, Giovanni (Orgs.). Democracia e construção do público no pensamento educacional brasileiro. Petrópolis: Vozes, 2002. p. 11-40.

CUNHA, Luiz Antônio. A universidade temporã. 0 ensino superior, da Colônia à 
Era Vargas. São Paulo: Editora UNESP, 2007.

EAGLETON, Terry. Marx e a liberdade. São Paulo: Editora UNESP, 1999.

FRIGOTTO, Gaudêncio. 0 enfoque da dialética materialista histórica na pesquisa educacional. In: FAZENDA, Ivani (Org.). Metodologia da pesquisa educacional. São Paulo: Cortez, 1997, p. 70-90.

GOMES, Maria Aldair; LIMA, Antonio Bosco. Os surgimentos dos programas alternativos como forma de ingresso na educação superior. In: Anped CentroOeste, 2010, Uberlândia, Anais...,Uberlândia, Editora UFU, 2010.

HELLER, Agnes. O cotidiano e a história. Rio de Janeiro: Paz e Terra, 1970.

KOSIK, Karel. Dialética do concreto. São Paulo: Paz e Terra, 2002.

LEFEBVRE, Henri. Sociologia de Marx. Rio de Janeiro: Forense-Universitária, 1979.

LUKÁCS, György. Socialismo e democratização. Escritos políticos 1956-1971. Rio de Janeiro: Editora UFRJ, 2008.

MARX, Karl. Manuscritos econômico-filosóficos. São Paulo: Martin Claret, 2005. . Crítica ao Programa de Gotha. Disponível em: <http://www.marxists. org>. Acesso em: 17 abr. 2007.

MERCADANTE QUER DAR BÔNUS... Jornal da Ciência 4.436, de 13/02/2012. Disponível em: <http://www.jornaldaciencia.org.br>. Acesso em: 14 fev.2012.

O FIM DO VESTIBULAR ...Jornal da Ciência 4317, de 08/08/2011. Disponível em: <http://www.jornaldaciencia.org.br>. Acesso em: 15 ago.2011.

ROSSATO, Ricardo. Universidade: nove séculos de história. Passo Fundo: Editora UFP, 2005.

SILVA, Maria das Graças Martins da; NOGUEIRA, Patrícia Simone. Expansão na educação superior e a política de democratização: avanços e contradições. In: SILVA, Maria das Graças Martins da (Org.). Políticas educacionais: faces e interfaces da democratização. Cuiabá: Editora UFMT, 2011, p. 13-38.

; VELOSO, Tereza Christina M. Aguiar. Acesso nas políticas da educação superior: dimensões e indicadores em questão. Revista Avaliação. 2012 (prelo).

SOUZA, Joiciane Aparecida de. Políticas de acesso à educação superior: flexibilização e democratização do ingresso na universidade. 2007. 239 f. Dissertação (Mestrado em Educação) - Programa de Pós-graduação, Universidade Federal de Uberlândia, 2007.

TRIVIÑOS, Augusto Nibaldo Silva. Introdução à pesquisa em ciências sociais. A pesquisa qualitativa em educação. São Paulo: Atlas, 1987.

WOOD, Ellen. Democracia contra o capitalismo. A renovação do materialismo histórico. São Paulo: Boitempo, 2003.

ZAGO, Nadir. Do acesso à permanência no ensino superior: percursos de estudantes universitários de camadas populares. Revista Brasileira de Educação, Anped, v. 11, n. 32, p. 226-370, maio/ago. 2006. 
Recebido em setembro de 2012

Aprovado em junho de 2013

Maria das Graças Martins da Silva é doutora em educação pela Universidade Federal do Rio Grande do Sul e docente do programa de pós-graduação em educação da Universidade Federal de Mato Grosso. Email: gracams2lahotmail.com

Tereza Christina Mertens Aguiar Veloso é doutora em educação e docente do programa de pós-graduação em educação e do curso de nutrição da Universidade Federal de Mato Grosso. Email: tecmavaterra.com.br 